\title{
Polyamines in Chloride-stressed Citrus Plants: Alleviation of Stress by Nitrate Supplementation via Irrigation Water
}

\author{
Yoel Bar', Akiva Apelbaum, Uzi Kafkafi' ${ }^{2}$, and Raphael Goren \\ The Kennedy-Leigh Centre for Horticultural Research, The Hebrew University of Jerusalem, Rehovot \\ 76100, Israel
}

Additional index words. 'Cleopatra' mandarin, Citrus reshni, 'Troyer' citrange (Poncirus $\times$ Citrus sinensis), putrescine, spermidine, spermine, salinity, ethylene

\begin{abstract}
A study was conducted to elucidate the effects of chloride in the irrigation water on growth and development of two citrus rootstocks. 'Cleopatra' mandarin (Citrus reshni Hort. ex Tan) is salt tolerant and 'Troyer' citrange (Poncirus $\times$ Citrus sinensis) is salt sensitive. Increasing chloride from 2 to $48 \mathrm{~mm}$ in the irrigation water resulted in increased leaf chloride levels, more severe damage of the leaves, and reduced branch growth. High chloride in the irrigation water also caused increased putrescine (PUT) and decreased spermine (SPM) contents of the leaves. These effects were slight in 'Cleopatra' but highly apparent in 'Troyer'. The symptoms caused by high chloride were associated with high PUT and low SPM levels in the leaves. PUT may be involved in the development of chloride toxic symptoms, and SPM may protect or have no effect on chloride plant injury. The leaf polyamine profiles of 'Troyer' and 'Cleopatra' under nonstress chloride conditions were different. In 'Troyer' leaves, PUT level was 9-fold higher than in 'Cleopatra'; in 'Cleopatra' leaves, SPM level was 25-fold higher than in 'Troyer'. Nitrate supplement to saline water reduced chloride accumulation in the leaves and reduced the increase in PUT. The possible connection between ethylene production and PUT and SPM levels in the leaves of stressed plants is discussed.
\end{abstract}

Citrus trees are known to be sensitive to salt (Chapman, 1968; Syvertsen et al., 1993; Zekri, 1993). Salinity in water for agricultural use is expressed in terms of chloride content. Irrigation water in Israel generally contains 2 to $16 \mathrm{~mm}$ chloride, but can go up to $30 \mathrm{~mm}$ (personal communication). Fruit trees are specifically sensitive to chloride taken up by the roots and accumulating in the leaves (Bernstein, 1981). Large amounts of chloride have been found in leaves and fruit juice of citrus trees irrigated with water high in chloride (Syvertsen et al., 1993). The degree of chloride damage to citrus trees varies with rootstock characteristics (Gallasch and Galton, 1989; Zekri, 1993). Shalhevet et al. (1974) found a 4.3\% decrease in yield for each $1 \mathrm{~mm}$ chloride increase in the irrigation water of 'Shamouti' orange trees grafted onto sweet lime rootstock and a 5.5\% yield decrease of 'Valencia' trees grafted onto sour orange rootstock. Tolerance by citrus trees to chloride is attributed to rate of chloride transport from the soil to the leaves (Cooper and Gorton, 1952).

In field surveys, chloride uptake and toxicity have been found to be influenced by nitrate. Haas (1928) reported chloride uptake by avocado trees to be higher at low concentrations of nitrate in the soil. Chapman and Liebig (1940) found that $20 \mathrm{~mm}$ chloride in the water only produced leaf toxic symptoms in citrus trees under nitrate-deficient conditions. The content of chloride in the leaves was $2.78 \%$ to $3.90 \%$ of the dry matter in nitrate-deficient plants and $0.53 \%$ in plants with ample nitrate supply. A competition between chloride and nitrate uptake has been shown in tomatoes (Kafkafi et al., 1982), melon, lettuce (Feigin, 1985), wheat (Soliman et al., 1994), strawberry (Awang and Atherton, 1994), and several other plant species (Kafkafi, 1984). Bar et al. (1992) showed

Received for publication 26 May 1995. Accepted for publication 12 Oct. 1995. The cost of publishing this paper was defrayed in part by the payment of page charges. Under postal regulations, this paper therefore must be hereby marked advertisement solely to indicate this fact.

${ }^{1}$ Supported by a grant to Y.B. from Emile Azoulay foundation.

${ }^{2}$ Dept. of Field Crops, Vegetables and Genetics. chloride uptake and toxicity decrease in avocado seedlings of sensitive and tolerant rootstocks by increased nitrate concentration in the nutrient solution.

Stress has been shown to alter the polyamine titer in various plants (Smith, 1990). The polyamines spermidine (SPD) and spermine (SPM) and the diamine putrescine (PUT) are ubiquitous in living organisms and are associated with a variety of physiological plant processes (Apelbaum, 1990; Goren et al., 1982; Smith, 1990). PUT, and to a lesser extent SPD and SPM, have been shown to accumulate in higher plants in response to various environmental stresses (Altman, 1989). PUT accumulation has been reported in response to $\mathrm{K}$ and $\mathrm{Mg}$ deficiencies (Smith, 1984), ammonium nutrition (Corey and Barker, 1989; Feng and Barker, 1993), NaCl stress (Altman, 1989), acid stress (Young and Galston, 1983), heat stress (Das et al., 1987), and osmotic stress (Flores and Galston, 1982b).

Most studies on salinity effects deal with $\mathrm{NaCl}$ stress, and the effects of sodium and chloride ions are not separated. Some attempts have been made in citrus to distinguish between effects of sodium and chloride on photosynthesis, leaf gas exchange, growth rate, and defoliation (Banuls and Primo Millo, 1992; Lloyd et al., 1987, 1989, 1990; Walker et al., 1982). The aim of the present study was to test the effects of chloride on plant growth, leaf mineral composition, free polyamine titer, and toxic symptoms in salt-sensitive and salt-tolerant citrus plants under various nitrate regimes.

\section{Materials and Methods}

One-year-old plants of the salt-tolerant 'Cleopatra' mandarin (Citrus reshni) rootstock and the salt-sensitive 'Troyer' citrange (Poncirus $\times$ Citrus sinensis) rootstock were grown in a greenhouse in 8-liter containers filled with sandy soil. The minimum temperatures during the experiment varied from 18 to $23 \mathrm{C}$ and the maximum temperatures varied from 27 to $33 \mathrm{C}$. The relative humidity ranged from $40 \%$ to $50 \%$ to $75 \%$ to $95 \%$. The field 


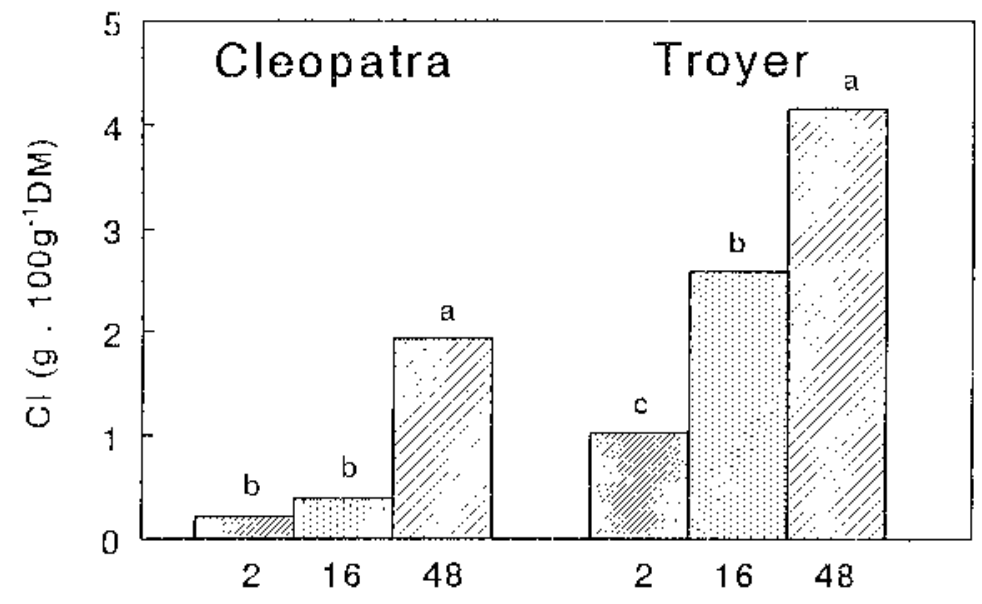

Gl (m) in solution
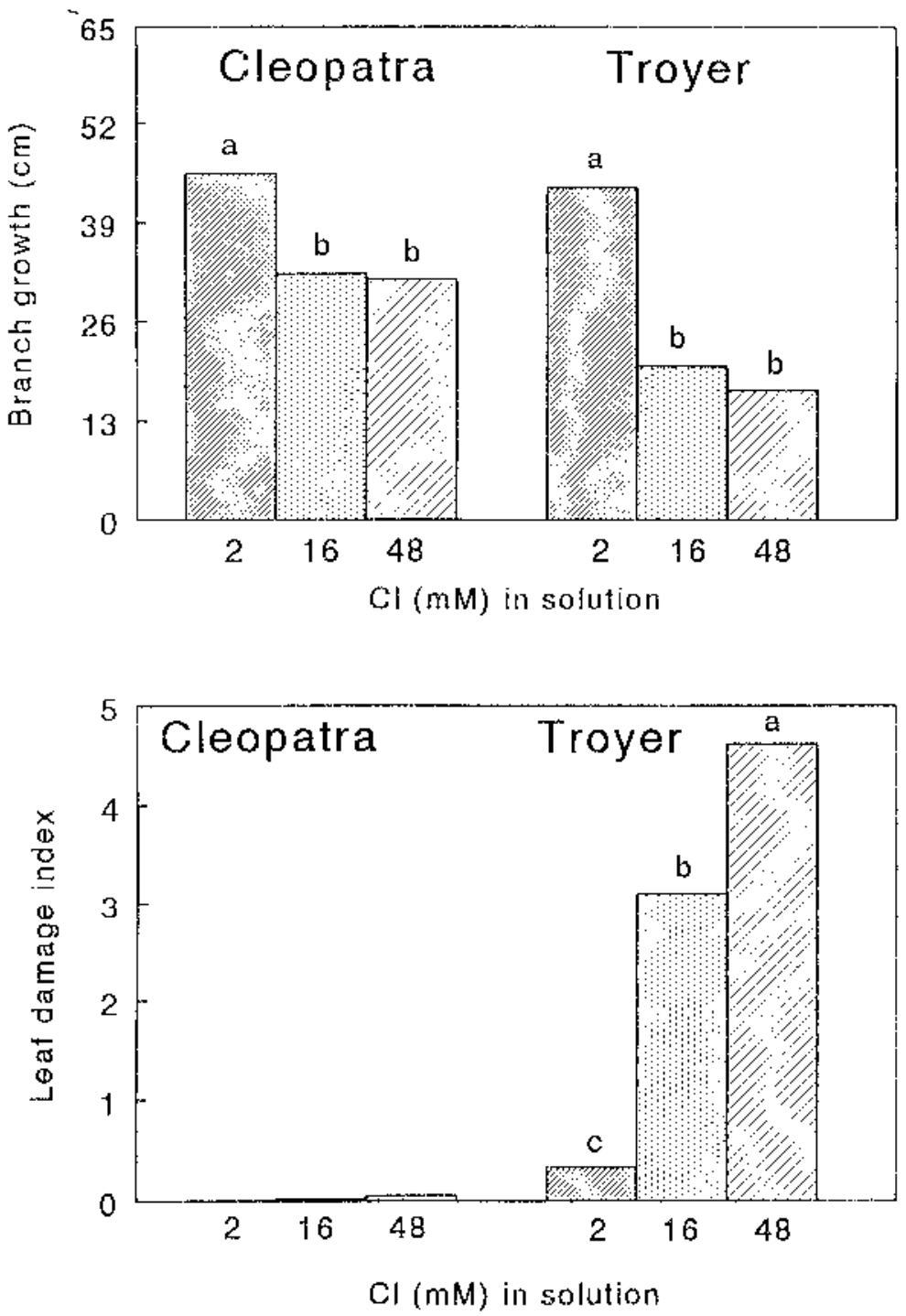

Fig. 1. Effects of chloride in the irrigation water on leaf chloride content, branch growth and shoot damage in 'Cleopatra' and 'Troyer' plants. Shoot damage was evaluated on a scale ranging from 0 (nodamage) to 5 (severe leaf scorching and branch-tip burning). Theirrigation water in all treatments contained $2 \mathrm{~mm}$ nitrate. Data are mean of three replicates for chloride and 18 replicates for branch growth and shoot damage. Means within each rootstock with different letter are statistically different $(P \leq 0.05)$. capacity of the soil was determined and the plants were irrigated with $40 \%$ excess of the water required to reach field capacity. Irrigation occurred at $25 \%$ to $30 \%$ water loss through evapotranspiration. The plants were irrigated with nutrient solutions containing 2, 16, or $48 \mathrm{~mm}$ chloride during the 3 month experimental period. The chloride nutrient solutions were also supplemented with 2,8 , or $16 \mathrm{~mm}$ nitrate, resulting in a total of nine treatments, with three plants in each treatment. The relevant chloride and nitrate concentrations were obtained with chloride and nitrate salts of $\mathrm{Mg}, \mathrm{Ca}$, and $\mathrm{K}$ at a charge equivalent cation ratio of 1:5:3, respectively. The only sodium in the nutrient solutions were chemical impurities of the salts and traces of sodium in the deionized water. Ten percent of the nitrogen in the nutrient solutions was supplied as ammonium to prevent high $\mathrm{pH}$ near the roots, which may lead to P and Fe deficiencies (Bar, 1989; Bar and Kafkafi, 1992). All solutions also included $0.6 \mathrm{~mm}$ monopotassium phosphate, $0.2 \mathrm{~mm}$ magnesium sulfate, $1 \mathrm{~mm}$ calcium sulfate, and a commercial mix of chelated micronutrients (Korateen, Fertilizers and Chemicals Ltd., Haifa, Israel).

The treatments were arranged in a completely randomized experimental design. Eight branches of similar size from each plant were marked at the beginning of the experiment to follow growth rate and toxic symptoms. The growth rate of each branch was obtained by subtracting the branch length at the beginning of the experimental period from the length at the end of the experiment. Shoot damage was evaluated according to the following scale: $0=$ no damage; $1=$ scorched leaf tips; $2=$ scorched leaf tips and margins; $3=$ one-third of the leaf scorched; $4=$ most of the leaf area scorched; $5=$ severe leaf scorching and branch tips burning.

Exogenous polyamines. To study the effects of exogenously applied polyamines, uniform mature leaves of both rootstocks were cut below the laminar abscission zone. The cut surfaces of the excised leaves were dipped for 10 to 14 days in water containing $0.0,0.01,0.1,1.0$, or $10.0 \mathrm{~mm}$ PUT, SPD, or SPM, or a combination of $10 \mathrm{~mm}$ PUT and $10 \mathrm{~mm}$ SPD or $10 \mathrm{~mm}$ SPM. There were five leaves in each treatment. The solutions were changed daily. The leaves were placed in a growth chamber at $28 \pm 1.5 \mathrm{C}$ under a 14 -h photoperiod at about $400 \mu \mathrm{E} \cdot \mathrm{m}^{-2} \cdot \mathrm{s}^{-1}$ and examined daily for damage.

Leaf mineral analysis. At the end of the 3 months, all the mature leaves were collected and oven-dried at $70 \mathrm{C}$ for $48 \mathrm{~h}$ and ground. Nitrogen, potassium, and magnesium were analyzed following wet digestion with $\mathrm{H}_{2} \mathrm{SO}_{4}$ and $\mathrm{H}_{2} \mathrm{O}_{2}$. Nitrogen was determined by colorimetry using Nessler's reagent. Magnesium and potassium were determined by inductively coupled plasma emission spectroscopy. Chloride was water extracted and analyzed by chloridometer.

Free polyamine determination. Leaves from the middle of the branches were collected from the treated plants at the end of the experiment. The leaves were ground with cold 5\% $\mathrm{HClO}_{4}$ (E. Merck, Darmstadt, Germany) using a prechilled mortar and pestle at an extraction ratio of $100 \mathrm{mg}$ fresh weight/ $\mathrm{ml} \mathrm{HClO}_{4}$. The homogenate was kept in an ice bath for $60 \mathrm{~min}$, vortexed, and centrifuged for $20 \mathrm{~min}$ at $27,700 \times g$ at $4 \mathrm{C}$. The precipitate was dissolved in $\mathrm{HClO}_{4}$, kept for $5 \mathrm{~min}$ in the ice bath, vortexed, and centrifuged. The first and second supernatant fractions were collected and stored at $-20 \mathrm{C}$ for free polyamine analysis (Flores and Galston, 1982a). Plant extracts and authentic standards of PUT, SPD, and SPM (Sigma Co., St. Louis) were benzoylated following the procedure described by Flores and Galston (1982a). Two milliliters of 2 
$\mathrm{N} \mathrm{NaOH}$ was added to $1 \mathrm{ml}$ of the $\mathrm{HClO}_{4}$ extract or to $50 \mu \mathrm{l}$ of the polyamine standards and vortexed. Eight microliters of benzoyl chloride (BDH Chemicals Ltd., Poole, England) was added and the mixture and incubated for $20 \mathrm{~min}$ at room temperature, then $2 \mathrm{ml}$ of saturated $\mathrm{NaCl}$ was added and the mixture was vortexed. Benzoyl-polyamines were extracted with $3 \mathrm{ml}$ diethyl ether (Frutarom Ltd., Haifa, Israel) and centrifuged at $2000 \times g$ for $5 \mathrm{~min}$, and $1.5 \mathrm{ml}$ of the ether phase was collected, evaporated to dryness under nitrogen stream, and redissolved in $150 \mu \mathrm{l}$ methanol (J.T. Baker Inc., Phillipsburg, N.J.). The benzoylated samples were stored at $-20 \mathrm{C}$. The polyamine levels were determined by a liquid chromatograph (Pharmacia LKB, Uppsala, Sweden) equipped with an ultraviolet detector (Micromeritics, Goshen Springs, Ga.) at $254 \mathrm{~nm}$. The solvent system consisted of isocratic 50\% acetonitrile (Frutarom Ltd., Haifa, Israel) and 50\% water at a flow rate of $0.7 \mathrm{ml} \cdot \mathrm{min}^{-1}$ (Flores and Galston, 1982a). This solvent system was found to produce the best separation of polyamine peaks. The benzoylated samples were injected into a fixed-volume $20-\mu 1$ loop and eluted at room temperature through a $4.6 \times 250-\mathrm{mm}, 5-\mu \mathrm{m}$ particle size C-18 reverse-phase column (Rainin Microsorb, Emeryville, Calif.). A computerized integration program (Barspec Inc., Mansfield, Ohio) was used to quantify polyamines by comparison with the polyamines standards.

Statistical analysis. Significant means were separated by Duncan's multiple range test.

\section{Results}

Leaf chloride and $N$ content, branch growth, and leaf scorching. Increasing concentration of chloride in the irrigation water used for 90 days resulted in higher leaf chloride content of the 'Cleopatra' and 'Troyer' plants. Leaf chloride content increased

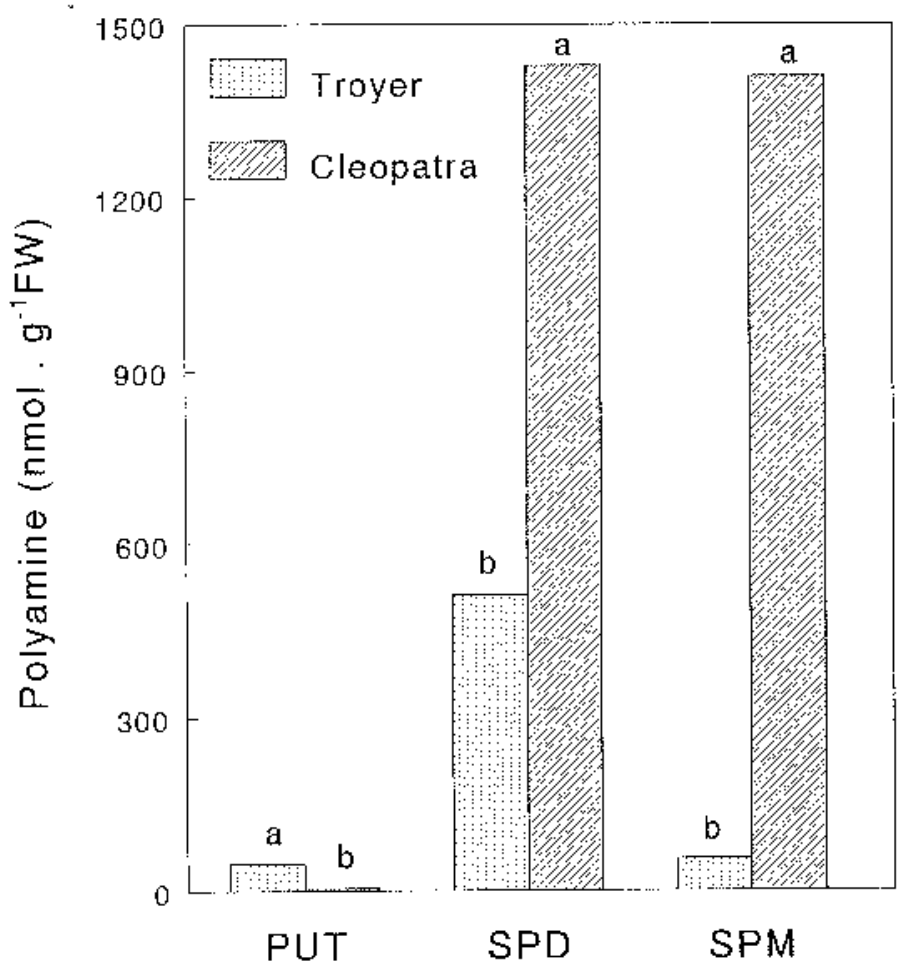

Fig. 2. Polyamine titer in leaves of 'Cleopatra' and 'Troyer' plants grown under nonstressful conditions using irrigation water containing $2 \mathrm{~mm}$ chloride and $2 \mathrm{~mm}$ nitrate. Data are mean of six replicates. Means within each polyamine with different letter are statistically different $(P \leq 0.05)$. more rapidly for 'Troyer' than 'Cleopatra' plants. Leaf chloride level of 'Cleopatra' plants irrigated with 2 mu chloride was $0.22 \%$, increased to $0.39 \%$ at $16 \mathrm{~mm}$, and showed a 9-fold increase to $1.93 \%$ when the plants were irrigated with water containing $48 \mathrm{~mm}$ chloride (Fig. 1). When the more sensitive 'Troyer' plants were irrigated with what can be considered high-quality water $(2 \mathrm{~mm}$ chloride), a relatively high leaf chloride level was recorded (1.02\%). In the leaves of 'Troyer' plants irrigated with $16 \mathrm{~mm}$ chloride, the chloride content was $2.58 \%$-7-fold higher than in the leaves of 'Cleopatra' plants irrigated with the same nutrient solution.

High concentrations of chloride in the water inhibited branch growth (Fig. 1). The inhibition was more pronounced in 'Troyer' than in 'Cleopatra'. When the chloride concentration in the water increased from 2 to $16 \mathrm{~mm}$, the growth of 'Cleopatra' branches was suppressed from 45.4 to $32.3 \mathrm{~cm}(29 \%)$, whereas the growth of 'Troyer' branches decreased from 43.5 to $20.1 \mathrm{~cm}(54 \%)$ (Fig. 1). Increasing the chloride concentration from 16 to $48 \mathrm{~mm}$ did not have any additional effect on either rootstock.

Increasing the chloride concentration in the irrigation water did not affect $\mathrm{N}$ level in the leaves of either rootstock. Adding a high concentration of nitrate to the water $(16 \mathrm{~mm})$ increased $\mathrm{N}$ level in 'Troyer' leaves by $40 \%$ (from $2.4 \%$ to $3.37 \%$ ) and in 'Cleopatra' leaves by $52 \%$ (from $2.08 \%$ to $3.16 \%$ ) above that recorded at $2 \mathrm{~mm}$ nitrate.

Increased damage was observed in leaves and branches of 'Troyer' in response to increased water chloride concentration (Fig. 1). In addition to the leaf damage observed in 'Troyer', the branch tips were scorched at high chloride concentrations. 'Cleopatra' leaves showed no damage with increasing chloride concentration, except for slight yellowing at $48 \mathrm{~mm}$ chloride.

Effect of chloride concentration in the irrigation water on leaf polyamine levels. A marked difference in leaf polyamine profiles was found between 'Troyer' and 'Cleopatra' irrigated with water containing $2 \mathrm{~mm}$ chloride, considered nonstressful conditions (Fig. 2). The content of PUT in 'Troyer' leaves was 9-fold higher than in 'Cleopatra' (48.4 vs. $5.1 \mathrm{nmol} \cdot \mathrm{g}^{-1}$ fresh weight), and the level of SPD in 'Cleopatra' leaves was 3-fold higher than in 'Troyer' (1428 vs. $512 \mathrm{nmol} \cdot \mathrm{g}^{-1}$ fresh weight). The most pronounced difference was found in SPM, which was 25-fold higher in 'Cleopatra' leaves than in 'Troyer' (1409 vs. $55.5 \mathrm{nmol} \cdot \mathrm{g}^{-1}$ fresh weight). When the plants were irrigated with water containing increasing chloride concentrations from 2 to $48 \mathrm{~mm}$, the level of PUT in the leaves of 'Cleopatra' increased from 5.1 to $13.8 \mathrm{nmol} \cdot \mathrm{g}^{-1}$ fresh weight and in 'Troyer' from 48.4 to 232.5 (Fig. 3), which is 17 -fold higher than that in the 'Cleopatra'. However, the levels of SPD and SPM remained unchanged in 'Cleopatra' leaves, whereas in 'Troyer' leaves the SPD level decreased from 512 to $406 \mathrm{nmol} \cdot \mathrm{g}^{-1}$ fresh weight and that of SPM from 55.5 to 31.1 (Fig. 3).

Polyamine treatments and leaf damage. When the cut surfaces of excised leaves were dipped in 0.01 or $0.1 \mathrm{~mm}$ solutions of PUT, SPD, or SPM, the leaves did not show any signs of damage for 14 days. Increasing the concentration of the polyamines to $1.0 \mathrm{~mm}$ resulted in leaf damage only with the PUT treatment, whereas leaves treated with up to $10 \mathrm{~mm}$ SPD or SPM for 14 days exhibited no damage (data not shown). 'Troyer' leaves were more sensitive than 'Cleopatra' leaves to the $1.0 \mathrm{~mm}$ PUT treatment, showing first signs of damage after 3 days; by day 5 a large portion of the leaves showed scorching damage and leaflet abscission. 'Cleopatra' leaves treated with $1.0 \mathrm{~mm}$ PUT did not show any damage for 10 days of treatment, after which they began to abscise. Treatment with $10 \mathrm{~mm}$ PUT resulted in more severe toxic symptoms in both rootstocks. Leaves treated with $10 \mathrm{~mm}$ SPD or SPM did not show any damage. Treatments with a combination of PUT and SPD or 

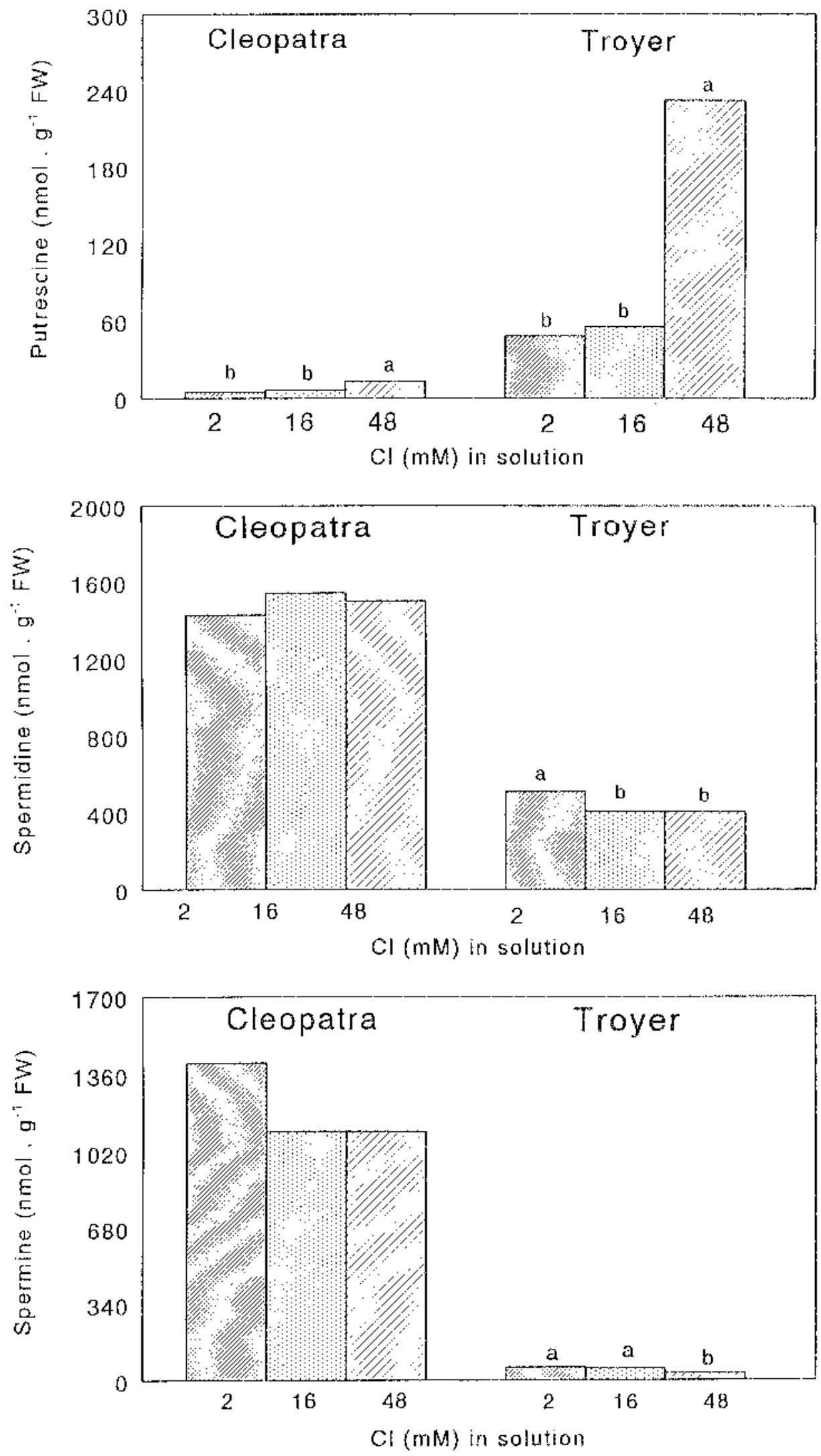

Fig. 3. Effect of chloride concentration in the irrigation water on putrescine, spermidine, and spermine content in the leaves of 'Cleopatra' and 'Troyer' plants. The irrigation water contained 2 mm nitrate. Note the different scales of the y axis among the figures. Data are mean of six replicates. Means within each rootstock with different letter are statistically different $(P \leq 0.05)$.
SPM did not affect the damage caused by PUT alone. Analysis of the treated leaves showed increased polyamine levels, which confirmed that polyamines had been taken up by the leaf tissue.

Nitrate supplementation of the irrigation water. Adding nitrate to chloride-containing irrigation water decreased leaf chloride content of 'Troyer' and 'Cleopatra' plants (Fig. 4). In 'Cleopatra', the reduction in chloride was more noticeable when the nitrate was added to water containing the higher chloride concentrations (16 and $48 \mathrm{~mm}$ ). In the case of 'Troyer', the reduced chloride content was already noticeable at the lower chloride concentration. Nevertheless, chloride levels in leaves of plants receiving the same treatment were always higher in 'Troyer' than in 'Cleopatra'.

A reduction in the severity of damage to 'Troyer' leaves and branches was recorded upon adding nitrate to irrigation water containing 16 or $48 \mathrm{~mm}$ chloride (Fig. 5). However, signs of chlorosis were apparent in 'Troyer' leaves of plants irrigated with water containing a high concentration of nitrate (16 mM).

Adding nitrate to the irrigation water enhanced branch growth in 'Cleopatra' when $8 \mathrm{~mm}$ nitrate was added to water containing $16 \mathrm{~mm}$ chloride (Fig. 5). However, the growth inhibition of 'Troyer' branches inflicted by chloride was markedly reduced by the adding $8 \mathrm{~mm}$ nitrate to water containing 2,16 , or $48 \mathrm{~mm}$ chloride (Fig. 5). A further increase in nitrate concentration did not have any significant effect on the branch growth.

In 'Cleopatra', adding $8 \mathrm{~mm}$ nitrate to the water with the highest chloride content $(48 \mathrm{~mm})$ caused a $51 \%$ reduction (from 13.8 to $6.7 \mathrm{nmol} \cdot \mathrm{g}^{-1}$ fresh weight) in the elevated level of PUT induced by the chloride (Table 1). The effect of nitrate addition was more pronounced in 'Troyer', where a $73 \%$ reduction (from 232.5 to $63.8 \mathrm{nmol} \cdot \mathrm{g}^{-1}$ fresh weight) in PUT level was recorded upon increasing the nitrate concentration from 2 to 8 mM in irrigation water containing $48 \mathrm{~mm}$ chloride (Table 1). Nitrate supplementation did not affect SPD levels in the leaves of either rootstock (Table 1), nor did it affect the SPM level in 'Cleopatra' leaves. However, a decrease of about $60 \%$ in the SPM level in 'Troyer' leaves was recorded at the low (2 $\mathrm{mm})$ and medium (16 mM) chloride concentrations upon increasing the nitrate concentration in the water from 2 to $8 \mathrm{~mm}$ (Table 1). 

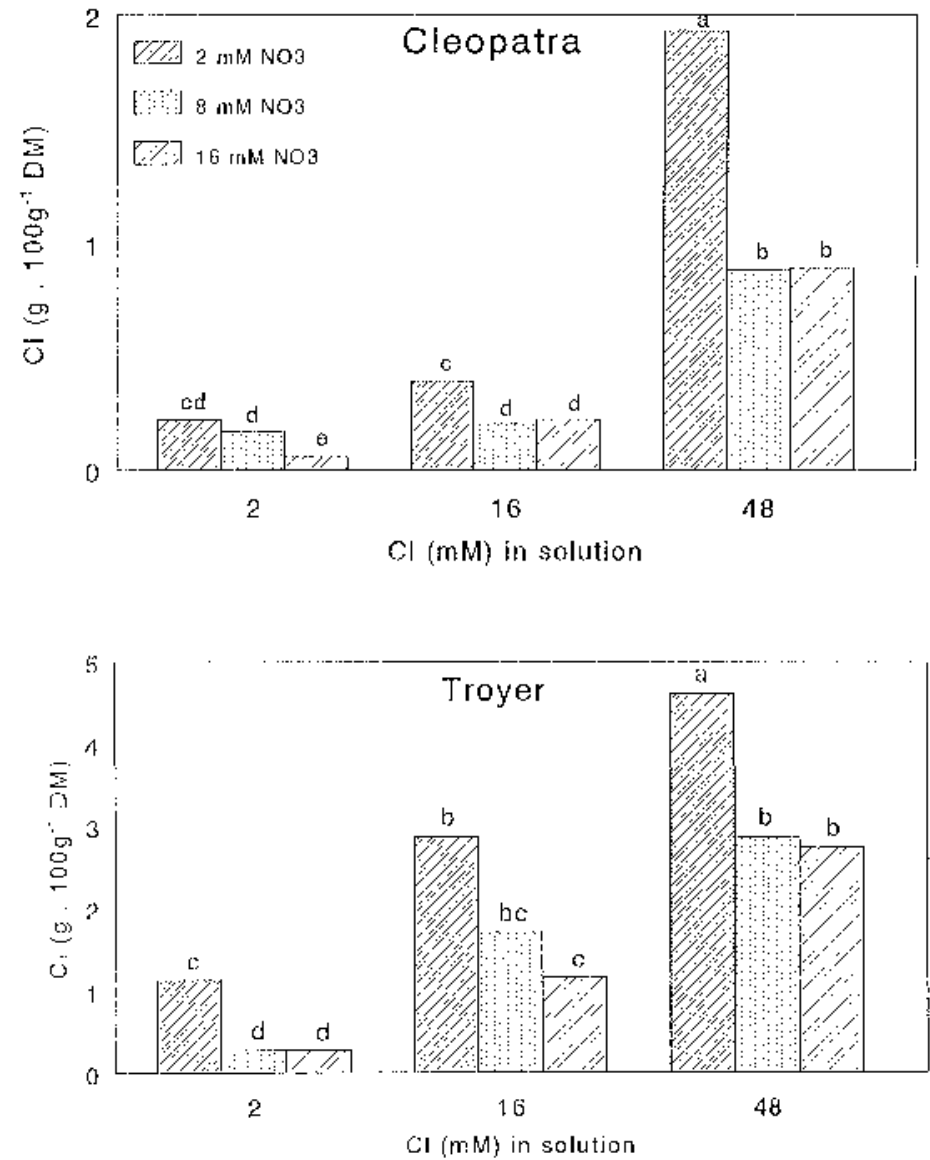

Fig. 4. Effects of nitrate supplementation on leaf chloride content in 'Cleopatra' and 'Troyer' plants irrigated with water containing increasing concentrations of chloride. Note the different scales of the y axis among the figures. Data are mean of three replicates. Means within each rootstock with different letter are statistically different $(P \leq 0.05)$.

\section{Discussion}

Studies on salinity effects mostly deal with the effect of $\mathrm{NaCl}$ on plant growth and development. The effects of sodium and chloride are usually not separated. An attempt was made here to isolate the influence of chloride on polyamine titer and plant development. The deleterious effect of chloride on plant development resulted in reduced branch growth and scorched leaves and branch tips. The salt-sensitive rootstock 'Troyer' showed damage even at the lowest chloride concentration of $2 \mathrm{~mm}$ (Fig. 1), which is considered good-quality irrigation water. In contrast, the salttolerant rootstock 'Cleopatra' showed a slight growth inhibition at 16 and $48 \mathrm{~mm}$ chloride concentrations and slight yellowing at 48 mu chloride.

Plants can withstand high chloride concentrations by restricting chloride uptake and transport to leaves and/or by an increased ability of their leaf tissue to tolerate high chloride concentrations (Bar, 1989). 'Cleopatra' leaves accumulated less chloride than 'Troyer' leaves if irrigated with water of the same chloride concentration. When leaf chloride concentration reached $2 \%$, no leaf damage was recorded in 'Cleopatra', whereas 'Troyer' leaves showed severe damage (Fig. 1). Thus, chloride resistance in 'Cleopatra' may be attributed to its ability to restrict chloride uptake and transport to the leaves and the ability of its leaf tissue to withstand high chloride concentrations.

The leaf polyamine profiles of 'Troyer' and 'Cleopatra' plants irrigated with good-quality water ( $2 \mathrm{~mm}$ chloride) were different; PUT level in 'Troyer' leaves was 9-fold higher than in 'Cleopatra', and the SPM level in 'Cleopatra' leaves was 25-fold higher than in 'Troyer' (Fig. 2). Hence, chloride sensitivity of 'Troyer' may be associated with high PUT and low SPM levels. Therefore, polyamine concentrations in the leaves may indicate salt tolerance in citrus. Salt-sensitive and salt-tolerant genotypes of rice have also been found to have similar different levels of polyamines (Krishnamurthy and Bhagwat, 1989). The difference between the polyamine titers of the two rootstocks increased when the plants were irrigated with water high in chloride (Fig. 3). As the differences in polyamine levels increased, the deleterious effects of chloride increased. High PUT levels may be harmful to plant tissue and high levels of SPD or SPM may have protective or no effects. To elucidate the role of the various polyamines in the chlorideinduced toxic symptoms, 'Troyer' and 'Cleopatra' leaves were allowed to take up PUT, SPD, or SPM, or a combination of PUT and SPD or SPM. Under these conditions, PUT caused damage to the leaves and probably plays a partial role in the toxic symptoms of plants irrigated with high chloride levels. Adding SPD or SPM did not appear to affect the toxic effects caused by PUT. The increased level of the diamine PUT and the reduced levels of the triamine SPD and the tetraamine SPM could be a result of the lower availability of the precursor propylamine moiety derived from $S$ adenosylmethionine (SAM). Competition between ethylene and polyamine pathways for the common precursor SAM has been shown (Even-Chen et al., 1982). Blockage of the SPD and SPM biosynthesis pathway could explain, at least in part, the PUT accumulation, assuming that PUT synthesis is maintained at a constant rate. SPD and SPM synthesis blockage could be attributed to a reduction in the availability of the propylamine moiety due to increased ethylene production. Recent studies (data not shown) revealed increased ethylene production in a salt-sensitive citrus rootstock in response to high chloride levels and a small decrease in ethylene evolution of a salt-tolerant rootstock. Whether PUT is a causal agent in the expression of stress symptoms or a consequence of the stress has not yet been established. Strogonov et al. (1972) suggested the toxic effects observed in salt-stressed plants are caused by the elevated salt content and the accumulation of PUT in the tissue. The results from the present study with applied polyamines support Strogonov's suggestion but not the suggested protective role of SPM (Altman, 1989; Young and Galston, 1983). Potassium and magnesium deficiencies are known to increase the PUT titer (Corey and Barker, 1989; Smith, 1984). In our study, K and $\mathrm{Mg}$ levels in the leaves were not affected by the chloride content in the water. Therefore, effect of chloride on PUT levels via $\mathrm{K}$ or $\mathrm{Mg}$ deficiencies can be ruled out. Adding chloride to the irrigation water did not significantly affect $\mathrm{N}$ level in the tissues of either rootstock. Therefore, it can be concluded that chloride at high levels does not exert its deleterious effects via the alteration of $\mathrm{N}$ content in the tissue.

Addition of nitrate to irrigation water with high concentrations of chloride resulted in reduced chloride accumulation in the leaves (Fig. 4) and, therefore, could account for the resultant alleviation of the toxic effects inflicted by high chloride levels (Fig. 5). The beneficial effect of increased nitrate nutrition was apparent in both rootstocks, but more pronounced in the chloride-sensitive 'Troyer', which displayed severe toxic symptoms of growth inhibition, leaf and branch-tip burns, and high PUT titer in response to increased chloride concentrations. The decrease in PUT level caused by enhanced nitrate nutrition could be considered as contributing to 

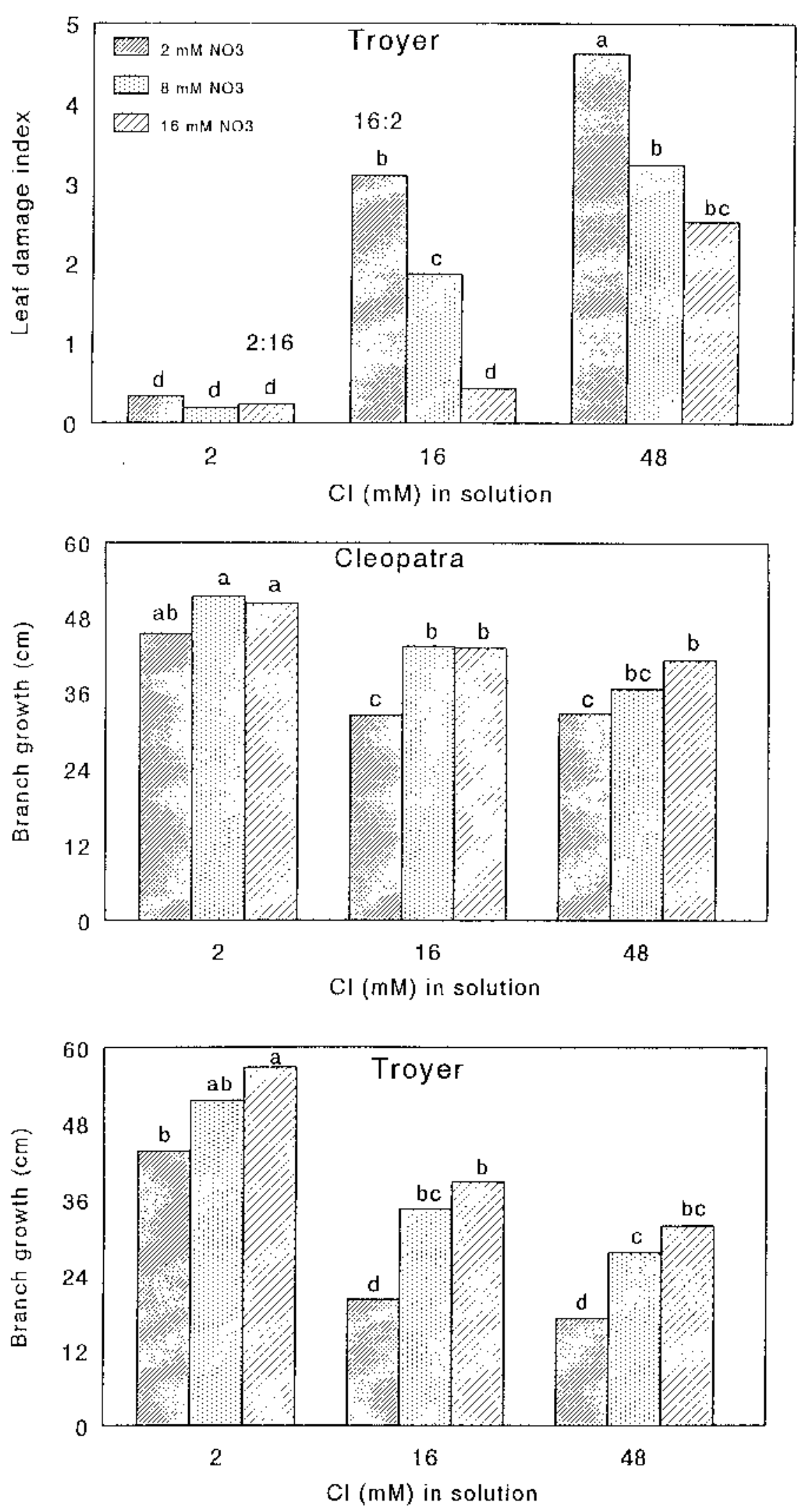

Fig. 5. Effects of nitrate supplementation on shoot damage in 'Troyer' plants and branch growth of 'Cleopatra' and 'Troyer' plants irrigated with water containing increasing concentrations of chloride. Shoot damage was evaluated on a scale ranging from 0 (no damage) to 5 (severe leaf scorching and branch-tip burning). Data are mean of 18 replicates. Means with different letter are statistically different $(P \leq 0.05)$. The values $2: 16$ and 16:2 indicate the bars with reciprocal molar concentrations of chloride:nitrate in two iso-osmotic treatments. the reduction of the toxic symptoms observed under high chloride conditions.

Although increasing nitrate concentration in the irrigation water caused a decrease in chloride level in the leaves, increasing chloride concentration in the water did not affect $\mathrm{N}$ level in the leaves. The nitrate anion taken up by the plant is metabolized and the $\mathrm{N}$ incorporated to organic compounds, transferring the negative charge to organic anions, while the chloride is not metabolized and maintains its negative charge (Cram, 1973). Thus, the chloride is accumulated within the plant as opposed to the nitrate anion. As a consequence, nitrate is preferentially absorbed by the plant over chloride. In addition, the presence of nitrate in the nutrient solution can inhibit the chloride flux into the root cells (Glass and Siddiqi, 1985) due to allosteric influence of nitrate on the site of chloride uptake (Cram, 1973).

The detrimental effects of chloride on citrus can be attributed to either an increase in the osmoticum of the nutrient solution or to the chloride ion's specific properties. Our results with 'Troyer' grown in iso-osmotic solutions with reciprocal chloride : nitrate molar ratios (2:16 vs. 16:2 mM) showed toxic symptoms only when chloride was the main anion (Fig. 5). It is suggested that, in the range of chloride concentrations tested, the toxic symptoms are not due to osmotic effects, rather to the chloride ion's toxic characteristics. The results obtained here suggest that adding nitrate can effectively alleviate chloride damage in citrus orchards irrigated with high-chloride containing water.

\section{Literature Cited}

Altman, A. 1989. Polyamines and plant hormones, $\mathrm{p}$. 121-145. In: U. Bachrach and Y.M. Heimer (eds.). The physiology of polyamines. vol. 2. CRC Press, Boca Raton, Fla.

Apelbaum, A. 1990. Interrelationship between polyamines and ethylene and its implication for plant growth and fruit ripening, p. 278-294. In: H.E. Flores, R.N. Arteca and J.C. Shannon (eds.). Polyamines and ethylene: Biochemistry, physiology, and interactions. Amer. Soc. Plant Physiol., Rockville, Md.

Awang, Y.B. and J.G. Atherton. 1994. Salinity and shading effects on leaf water relations and ionic composition of strawberry plants grown on rockwool. J. Hort. Sci. 69:377-383.

Banuls, J. and E. Primo Millo. 1992. Effects of chloride and sodium on gas exchange parameters and water relations on Citrus plants. Physiol. Plant. 86:115123.

Bar, Y. 1989. Nitrate nutrition as a tool to reduce chloride toxicity in avocado. MS thesis. Faculty of Agr., Hebrew Univ. of Jerusalem, Israel.

Bar ,Y. and U. Kafkafi. 1992. Nitrate-induced irondeficiency chlorosis in avocado (Persea americana Mill.) rootstocks and its prevention by chloride. J. Plant Nutr. 15:1739-1746.

Bar, Y., U. Kafkafi, and E. Lahav. 1992. Reducing chloride toxicity in avocado by nitrate, p. 373. In: C.J. Lovatt (ed.). Proc. of the 2nd World Avocado Congr.

Bernstein, L. 1981. Effects of salinity and soil water 
Table 1. Effects of nitrate supplementation to the irrigation water on putrescine, spermidine and spermine levels in leaves of 'Cleopatra' and 'Troyer' plants irrigated with water containing increasing concentrations of chloride. Data are mean of six replicates. Means within each column with different letter are statistically different $(P \leq 0.05)$. All the differences between rootstocks are statistically different $(P \leq 0.01)$.

\begin{tabular}{|c|c|c|c|c|c|c|}
\hline \multirow{2}{*}{$\begin{array}{l}\mathrm{Cl}: \mathrm{NO}_{3} \\
(\mathrm{mM})\end{array}$} & \multicolumn{2}{|c|}{ Putrescine } & \multicolumn{2}{|c|}{ Spermidine } & \multicolumn{2}{|c|}{ Spermine } \\
\hline & Troyer & $\overline{\text { Cleopatra }}$ & Troyer & Cleopatra & Troyer & Cleopatra \\
\hline $2: 2$ & $48.4 \mathrm{bc}$ & $5.1 \mathrm{~b}$ & $512 a$ & 1428 & $55.5 \mathrm{a}$ & 1409 \\
\hline $2: 8$ & $37.0 \mathrm{c}$ & $5.5 \mathrm{~b}$ & $303 \mathrm{~b}$ & 1455 & $22.5 \mathrm{c}$ & 991 \\
\hline $2: 16$ & $19.3 \mathrm{~cd}$ & $6.8 \mathrm{~b}$ & $437 \mathrm{ab}$ & 1440 & $20.9 \mathrm{c}$ & 929 \\
\hline $16: 2$ & $56.0 \mathrm{~b}$ & $6.5 \mathrm{~b}$ & $408 \mathrm{~b}$ & 1543 & $50.7 \mathrm{a}$ & 1111 \\
\hline $16: 8$ & $25.9 \mathrm{~cd}$ & $6.0 \mathrm{~b}$ & $362 \mathrm{~b}$ & 1549 & $20.4 \mathrm{c}$ & 996 \\
\hline $16: 16$ & $16.1 \mathrm{~d}$ & $6.1 \mathrm{~b}$ & $415 b$ & 1645 & $24.8 \mathrm{c}$ & 840 \\
\hline $48: 2$ & $232.5 \mathrm{a}$ & $13.8 \mathrm{a}$ & $406 \mathrm{~b}$ & 1499 & $31.1 \mathrm{bc}$ & 1110 \\
\hline $48: 8$ & $63.8 \mathrm{~b}$ & $6.7 \mathrm{~b}$ & $373 \mathrm{~b}$ & 1892 & $41.6 \mathrm{~b}$ & 1012 \\
\hline $48: 16$ & $33.8 \mathrm{c}$ & $5.2 \mathrm{~b}$ & $406 \mathrm{~b}$ & 2375 & $40.0 \mathrm{~b}$ & 998 \\
\hline
\end{tabular}

regime on crop yields, p. 47-64. In: D. Yaron (ed.). Salinity in irrigation and water resources. Marcel Dekker, New York.

Chapman, H.D. 1968. The mineral nutrition of citrus, p. 127-289. In: W. Reuther, L.D. Batchelor, and H.J. Webber (eds.). The citrus industry. vol. 2. Univ. of California.

Chapman, H.D. and G.F. Liebig, Jr. 1940. Nitrate concentration and ion balance in relation to citrus nutrition. Hilgardia 13:141-173.

Cooper, W.C. and B.S. Gorton. 1952. Toxicity and accumulation of chloride salts in Citrus on various rootstocks. Proc. Amer. Soc. Hort. Sci. 59:143-146.

Corey, K.A. and A.V. Barker. 1989. Ethylene evolution and polyamine accumulation by tomato subjected to interactive stresses of ammonium toxicity and potassium deficiency. J. Amer. Soc. Hort. Sci. 114:651655.

Cram, W.J. 1973. Internal factors regulating $\mathrm{NO}^{-}$and $\mathrm{Cl}^{-}$influx in plant cells. J. Expt. Bot. 24:328-341.

Das, S., R. Basu, and B. Ghosh. 1987. Heat stress induced polyamine accumulation in cereal seedlings. Plant Physiol. Biochem. 14:108-116.

Even-Chen, Z., A.K. Matoo and R. Goren. 1982. Inhibition of ethylene biosynthesis by aminoethoxyvinylglycine and by polyamines shunts label from $\left[3,4-{ }^{14} \mathrm{C}\right]$ methionine into spermidine in aged orange peel discs. Plant Physiol. 69:385-388.

Feigin, A. 1985. Fertilization management of crops irrigated with saline water. Plant Soil 89:285-299.

Feng, J. and A.V. Barker. 1993. Polyamine concentration and ethylene evolution in tomato plants under nutritional stress. HortScience 28:109110.

Flores, H.E. and A.W. Galston. 1982a. Analysis of polyamines in higher plants by high performance liquid chromatography. Plant Physiol. 69:701-706.

Flores, H.E. and A.W. Galston. 1982b. Polyamines and plant stress: Activation of putrescine biosynthesis by osmotic shock. Science 217:1259-1261.

Gallasch, P.T. and G.S. Galton. 1989. Selecting salt-tolerant citrus rootstocks. Austral. J. Agr. Res. 40:137-144.

Glass, A.D.M. and M.Y. Siddiqi. 1985. Nitrate inhibition of chloride influx in barley: implications for a proposed chloride homeostat. J. Expt. Bot. 36:556-566.

Goren, R., N. Palavan and A.W. Galston. 1982. Changes in polyamine titer in etiolated pea seedlings in relation to red light treatment. Plant Physiol. 23:19-26.
Haas, A.R.C. 1928. Relation of chloride content to tip-burn of avocado leaves. Yrbk. Calif. Avocado Soc. 12:57.

Kafkafi, U. 1984. Plant nutrition under saline conditions, p. 319-338. In: I. Shainberg and J. Shalhevet (eds.). Soil salinity under irrigation. Ecological studies no. 51., Springer-Verlag, Berlin.

Kafkafi, U., N. Valoras, and J. Letey. 1982. Chloride interaction with nitrate and phosphate nutrition in tomato. J. Plant Nutr. 5:1369-1385.

Krishnamurthy, R. and K.A. Bhagwat. 1989. Polyamines as modulators of salt tolerance in rice cultivars. Plant Physiol. 91:500-504.

Lloyd, A., P.E. Kriedemann, and A. Aspinall. 1989. Comparative sensitivity of 'Prior Lisbon' lemon and 'Valencia' orange trees to foliar sodium and chloride concentrations. Plant Cell Environ. 12:529-540.

Lloyd, A., P.E. Kriedemann, and A. Aspinall. 1990. Contrast between Citrus species in response to salinisation. Physiol. Plant. 78:236-246.

Lloyd, A., P.E. Kriedemann, and J.P. Syvertsen. 1987. Salinity effects on leaf water relations and gas exchange of 'Valencia' orange, Citrus sinensis (L.) Osbeck, on rootstocks with different salt exclusion characteristics. Austral. J. Plant Physiol. 14:605-617.

Shalhevet, J., D. Yaron, and U. Horowitz. 1974. Salinity and citrus yieldAn analysis of results from a salinity survey. J. Hort. Sci. 49:15-27.

Smith, T.A. 1984. Putrescine and inorganic ions. Adv. Phytochem. 18:7-54.

Smith, T.A. 1990. Plant polyamines. Metabolism and function, p. 1-23. In: H.E. Flores, R.N. Arteca, and J.C. Shannon (eds.). Polyamines and ethylene: Biochemistry, physiology, and interactions. Amer. Soc. Plant Physiol., Rockville, Md.

Soliman, M.S., H.G. Shalabi, and W.F. Campbell. 1994. Interaction of salinity, nitrogen, and phosphorus fertilization on wheat. J. Plant Nutr. 17:1163-1173.

Strogonov, B.P., N.I. Shevyakova, and V.V. Kabanov. 1972. Diamines in metabolism of plants under conditions of salinization. Fiziol. Rast. (Moscow) 19:1098-1104.

Syvertsen, J.P., M.L. Smith, and B.J. Boman. 1993. Tree growth, mineral nutrition and nutrient leaching losses from soil of salinized citrus. Agr. Ecosys. Environ. 45:319-334.

Walker, R.R., E. Torokfalvy, and W.J.S. Dowton. 1982. Photosynthetic responses of the citrus varieties Rangpur lime and Etrog citron to salt treatments. Austral. J. Plant Physiol. 9:783-790.

Young, N.D. and A.W. Galston. 1983. Putrescine and acid stress. Plant Physiol. 71:767-771.

Zekri, M. 1993. Seedling emergence, growth and mineral concentration of three citrus rootstocks under salt stress. J. Plant Nutr. 16:1555-1568. 